Revue d'histoire de l'Amérique française

REVUE D.HISTOIRE DE L'AMÉRIQUE FRANÇAISE

\title{
Chronique : Olivier Maurault (1886-1968)
}

\section{Guy Frégault}

Volume 22, numéro 2, septembre 1968

URI : https://id.erudit.org/iderudit/302793ar

DOI : https://doi.org/10.7202/302793ar

Aller au sommaire du numéro

Éditeur(s)

Institut d'histoire de l'Amérique française

ISSN

0035-2357 (imprimé)

1492-1383 (numérique)

Découvrir la revue

Citer ce document

Frégault, G. (1968). Chronique : Olivier Maurault (1886-1968). Revue d'histoire de l'Amérique française, 22(2), 348-349. https://doi.org/10.7202/302793ar d'utilisation que vous pouvez consulter en ligne.

https://apropos.erudit.org/fr/usagers/politique-dutilisation/ 


\section{CHRONIQUE DE L'INSTITUT}

\section{OLIVIER MAURAULT (1886-1968)}

Je me le rappelle comme je le vis pour la première fois, il y a trente ans. C'était à l'ancienne université de la rue Saint-Denis, un soir, entre deux cours. Il se disposait probablement à présider quelque cérémonie. Le manteau romain tombait en plis élégants, le sourire étincelait, le lorgnon aussi, et sans doute également les propos qu'il tenait aux figurants qui l'entouraient.

Personne n'est moins impressionnable qu'un garçon de vingt ans qui refuse d'être impressionné. Le personnage me cacha l'homme, comme il l'a soustrait, je n'en doute pas, aux yeux d'un grand nombre de ses contemporains. Mais le moyen de retrouver un homme derrière six doctorats honorifiques et les présidences à la douzaine, depuis celle de la Société Royale du Canada jusqu'à celle du comité canadien de la Gallery of Living Catholic Authors, en passant par celle de la Société des écrivains canadiens et celle de la Société historique de Montréal, sans oublier celle de la Société canadienne d'histoire de l'Eglise catholique? Et puis, il y avait les décorations, plus nombreuses encore que les présidences: commandeur de l'Ordre Equestre du Saint-Sépulcre, chapelain de l'Ordre de Malte, compagnon de Saint-Michel et de Saint-Georges, chevalier de l'Etoile Noire; Chevalier du Bon Parler français...

Tout cela était proprement impardonnable, surtout dans une société comme celle qu'il a connue et que nous connaissons encore, où l'on pratique avec impartialité le pardon du talent comme celui de la médiocrité, à la condition expresse qu'ils ne soient pas brillants. Or Olivier Maurault était brillant: brillant causeur, brillant écrivain, brillant ecclésiastique, brillant critique, brillant conférencier. (On me répondra, bien sûr, que tout ce qui brille n'est pas or; et que puis-je contre cette sagesse, sinon de rappeler qu'il ne suffit peut-être pas d'être terne pour se révéler d'un solide métal ?)

Sa carrière semblait insolente de bonheur. Ordonné prêtre en 1910, à l'âge de 24 ans, Maurault fréquente, en 1911-1912, l'Institut Catholique de Paris. Ensuite, professeur au Collège 
de Montréal jusqu'en 1915, il devient vicaire à la paroisse SaintJacques, en même temps que chapelain de l'Ecole Polytechnique. En 1926, le voici curé de Notre-Dame. Il dirige le Collège Grasset de 1929 à 1934. Cette année-là, il est nommé, à quarante-huit ans, recteur de l'Université de Montréal, poste qu'il conserve jusqu'en 1955.

L'institution dont il prenait la tête en 1934 , en pleine crise économique, traversait des années pénibles. Quelques grands noms l'illustraient. Celui de Groulx était le plus grand de tous. Mais c'était, au fond, un ensemble d'écoles professionnelles au service d'une collectivité qui attendait d'elle, essentiellement, qu'elle lui donnât un Establishment d'avocats, de médecins, de pharmaciens, de dentistes... L'autorité du recteur connut des hauts et des bas. Je crois que la foi de cet homme éprouvé et le prestige personnel de cet homme brillant, disert, civilisé, n'ont pas peu contribué à assurer à l'Université le respect indispensable à son modeste rayonnement. Les hommes créent les institutions à leur image et à leur ressemblance. Mais les institutions conditionnent les hommes.

Quant à nous, nous n'oublions pas que le recteur Maurault a été de ceux qui ont soutenu le chanoine Groulx lorsque celui-ci lança, voilà vingt et un ans, l'Institut et la Revue d'histoire de l'Amérique française. Il avait écrit plusieurs livres d'histoire et de critique, dont Le Petit Séminaire de Montréal, Brièvetés, Nos Messieurs, Marges d'histoire, Propos et portraits, La Paroisse (comme pour les présidences et les décorations, il faut, ici encore, abréger).

Ouvrons le premier numéro de notre Revue (juin 1947). Les deux aspects de la personnalité de Mgr Maurault y sont mises en lumière. D'abord, son nom paraît au verso de la couverture, en tête - cela va de soi - de la courte liste des membres honoraires. Voilà, dirais-je, pour la galerie. Ensuite, son nom figure au sommaire. Olivier Maurault signe une note sur "Cavelier de La Salle au Texas". Il livre aussi au public l'allocution qu'il vient de prononcer, le 22 avril, en décernant à Jean Delanglez, auteur de savantes et austères études historiques, un doctorat ès lettres "honoris causa".

Ami de notre maison, ami de Lionel Groulx, Olivier Maurault n'aurait pas mérité ce titre s'il n'avait d'abord été un bon serviteur du Québec.

\author{
GUY FrÉGAULT, \\ Président de l'Institut d'Histoire \\ de l'Amérique française
}

